\title{
Why Medical Schools Are Tolerant of Unethical Behavior
}

Edison Iglesias de Oliveira Vidal, $M D, P b D^{1}$

Vanessa dos Santos Silva, MD, PbD ${ }^{1}$

Maria Fernanda dos Santos, OT, MPH student ${ }^{2}$

Alessandro Ferrari Jacinto, $M D P b D^{1}$

Paulo José Fortes Villas Boas, MD, $P b D^{1}$

Fernanda Bono Fukusbima, MD, $\mathrm{PbD}^{3}$

'Internal Medicine Department, Universidade Estadual Paulista (UNESP), Botucatu, Sao Paulo, Brazil

${ }^{2}$ Public Health Department, Universidade Estadual Paulista (UNESP), Botucatu, Sao Paulo, Brazil

${ }^{3}$ Anesthesiology Department, Universidade Estadual Paulista (UNESP), Botucatu, Sao Paulo, Brazil

Conflicts of interest: authors report none.

\section{CORRESPONDING AUTHOR}

Edison Iglesias de Oliveira Vidal Departamento de Clínica Médica Faculdade de Medicina de Botucatu - UNESP

Rubião Jr. SN

Botucatu - Sao Paulo, Brazil. 18618-970

eiovidal@fmb.unesp.br

\begin{abstract}
The exposure to unethical and unprofessional behavior is thought to play a major role in the declining empathy experienced by medical students during their training. We reflect on the reasons why medical schools are tolerant of unethical behavior of faculty. First, there are barriers to reporting unprofessional behavior within medical schools including fear of retaliation and lack of mechanisms to ensure anonymity. Second, deans and directors do not want to look for unethical behavior in their colleagues. Third, most of us have learned to take disrespectful circumstances in health care institutions for granted. Fourth, the accreditation of medical schools around the world does not usually cover the processes or outcomes associated with fostering ethical behavior in students. Several initiatives promise to change that picture.
\end{abstract}

Ann Fam Med 2015;13:176-180. doi: 10.1370/afm.1763.

\section{THE ORATOR'S SPEECH}

$\mathrm{R}$ ecently, we attended the graduation ceremony of medical graduates at our medical school. It is satisfying to see the glowing faces of our students and their families, as these young men and women perform this last ritual towards becoming physicians. As the orator gave her speech, she thanked the professors and health care professionals who had taught her and fellow graduates important lessons of competent and humane care of sick patients, and also faculty who had provided them with examples of "pure unethical behavior." She justified her "gratitude" by saying that they had learned 2 eloquent lessons: how to behave professionally and how not to behave toward patients, their families, and colleagues.

In the next few days after the ceremony, we asked other faculty members and other professionals who had attended the graduation ceremony about their thoughts on the speech. Surprisingly, no one seemed uneasy about the not-so-subtle allegation of unethical behavior of faculty in our medical school. In fact, no one had approached the orator or her fellow graduates to verify the claims of disrespectful and unethical behavior.

We wondered what would have happened if that speech had been presented at another type of institution. Would the CEO respond by reaffirming the organization's commitment to ethical behavior? Would the orator and her fellow graduates be asked to substantiate the claims and assist with investigations to protect not only the organization's customers and employees, but also the organization's mission and reputation? We hope that the answer to those questions would be yes.

Why then is unethical behavior tolerated in medical schools? This is not a local problem and unfortunately there are several examples in the medical literature describing how common such unprofessional situations are around the world. ${ }^{3-8}$ Most, if not all, medical schools confront harassment and discrimination as described by a recent systematic review. ${ }^{9}$

For the purposes of this essay we will define unethical behaviors as those that infringe any aspect of the medical code of ethics. We will also consider professionalism as a subset of health care ethics as proposed by Brody and Doukas ${ }^{1}$ and as "any intent, action or words that foster trustworthy relationships" as wisely defined by Shapiro and colleagues. ${ }^{2(169)}$ 
The student whose speech prompted our reflections told us that by "pure unethical behavior" she meant experiences of disrespectful and unprofessional patient care, such as performing medical procedures against the will of patients that were fully capable of decisionmaking, withholding diagnostic information from patients, making derogatory comments about patients in their presence, or allowing medical students and unprepared residents to care for severely ill patients with little or no supervision. She also meant the public humiliation or harassment (including examples of sexism, homophobia, and racism) of students, residents, nurses, and other physicians.

\section{REASONS WHY}

Despite the best intentions of medical schools, medical students and residents commonly develop declining empathy, ethical erosion, and cynicism during their training. ${ }^{10-12}$ This phenomenon has been attributed to the "hidden curriculum." The hidden curriculum has been described as learning derived from the organizational environment and culture within an institution. Examples include the behavior and attitudes of faculty and other professionals, as well as other implicit and taken-for-granted rules for survival within the institution..$^{13}$ The persistence of this problem and the relative paucity of initiatives to reduce the exposure of students, residents, and patients to unethical and unprofessional behavior prompts the question of why medical schools are tolerant of unacceptable behaviors. We believe the answer to this question lies in several factors associated with the general organization and culture of health care organizations.

Barriers to reporting unprofessional behavior include fear of retaliation, lack of anonymity of reporting mechanisms, the perception that complaining is a sign of weakness, and the belief that one needs to be "strong" to become a doctor. What student, resident, nurse, or physician will report an incompetent or unethical professional if there is the slightest risk that his or her career may be severely jeopardized in the future $?^{14}$ Institutions that have created anonymous reporting mechanisms against unprofessional behavior commit to not only improving their learning/practicing environment but also to enhancing patient safety. ${ }^{2,15,16}$

We believe that most deans, directors, and chiefs do not want to look for unethical and unprofessional behavior in their colleagues. These are sensitive matters about which some may feel uncomfortable or unknowledgeable. Few leaders have been trained to conduct interventions about disruptive behaviors with peers. Moreover, it seems ignorance is bliss; it is easier to remain unaware of unethical behavior than to be aware of it and forced to deal with it. A recent editorial described the way the program director and the department chair of a medical school in the United States reacted when a case of recurrent resident mistreatment was brought to their attention. ${ }^{17}$

"... it was as if I had dropped a dead rodent on the floor. They paid attention bud did not want to touch it. Eventually they confirmed what the residents had said. The faculty member had his personality 'challenges' but provided good care, was a brilliant researcher, and was working on his issues. He had been consulting with a therapist to control his outbursts, and everyone was hoping the incidents I had heard about were a thing of the past." ${ }^{17(\mathrm{p} 693)}$

Even though we recognize that this example cannot be regarded as representative of the way most leaders in medical schools deal with the issue of resident mistreatment, it shows that that leaders can choose to turn a blind eye to such behaviors even when surveillance systems such as those by the Accreditation Council for Graduate Medical Education and the Liaison Committee on Medical Education (LCME) exist.

Systemic disrespect is pervasive in health care institutions. ${ }^{18}$ We have become accustomed to long waiting times for patients in ambulatory medicine waiting rooms, excessive workloads for members of the health care team, and the failure to acknowledge mistakes, to apologize, and to provide full explanations when things go wrong. We believe that those examples of systemic disrespect have set the stage for other less frequent yet more disruptive events. It is easy to forget that every medical professor, chief, or director was once a medical student, and medical students are individuals striving to adapt to a new world-a world that involves a new language, signs, rituals, and customs. In making that transition, we became accustomed to an environment with some shortcomings that should never have been taken for granted.

Finally, the accreditation of medical schools around the world does not usually cover the processes or outcomes associated with fostering ethical behavior. In fact, very few countries have accreditation criteria for graduate and postgraduate education specific for medical education. ${ }^{19}$ For instance, in Brazil, the process of renewing the accreditation of a medical school is essentially the same as in remarkably different fields (eg, engineering and chemistry). ${ }^{20}$

A comprehensive review about the accreditation process of medical schools around the world is beyond the scope of this manuscript. Nevertheless, it is important to note that although the current guidance by the World Federation for Medical Education states that every medical school must incorporate medical ethics in their curricula, it does not include in the same 
specific and mandatory way any recommendation for the assessment of ethical/professional behavior of their faculty or of the learning environment. ${ }^{21}$ On the other hand, the current accreditation system promoted by the LCME in the United States requests supporting evidence that medical schools have effective mechanisms to prevent and manage cases of student mistreatment. ${ }^{22}$ In addition, the LCME Medical Education Database demands medical schools compare their proportion of medical students' reports of harassment and discrimination as evaluated by the American Academy of Medical Colleges' graduation questionnaire to a national average. Incorporating similar measures into the assessment of the quality of medical schools around the world would represent a major step toward real change in medical education globally. ${ }^{23}$

\section{IMPLICATIONS}

Concerns about the ethical formation of medical students have implications beyond the medical school setting. Indeed, it has been asserted that a major reason why health care systems have been slow in reducing preventable adverse events is the long-standing and hidden culture of dysfunctional and disrespectful behavior within health care institutions. ${ }^{18,24-26}$ Intimidating and disruptive behaviors in health care organizations lead to medical errors, adverse preventable outcomes, and increased costs. ${ }^{27-29}$

For most health care organizations there is a chasm between the official version of their aims, putting patients at the center of their endeavors, and the real culture of those institutions, which place medical hierarchy in the center. ${ }^{8,30}$ This veiled conflict between explicit and implicit values sets the stage for distorted professionalism, cynicism, and arguably a degree of self-delusion. Professionals may start to view "culturally appropriate" but still ethically unacceptable and unprofessional behaviors as manifestations of good medical practice. If we add the rising demands for "efficiency,"seeing a larger number of patients with fewer resources, and the increase in the workload and responsibilities of health care providers in general, - we will find fertile ground not only for disruptive behaviors but also for the identity crisis of modern medical practice as exemplified by the rise of commercialism against values such as altruism and compassion. ${ }^{2,31}$

Philip Zimbardo, in his book The Lucifer Effect: Understanding How Good People Turn Evil, states that situational forces can induce good people to depart from ethical paths via mechanisms such as obedience to authority, deindividuation, self-justification, and rationalization, all of which are remarkably common in the learning of medicine. ${ }^{32} \mathrm{He}$ argues that leaders must share the responsibility for the occurrence of unethical behaviors (and their consequences) within their institutions. Leaders should be aware and should strive to stop, mitigate, and prevent unethical behaviors. He also speaks of "administrative evil," when standard operational procedures within an organization inflict harm or suffering on individuals by blindly following a cold bureaucratic rationality committed for the ends but not the means to those ends. Zimbardo's considerations were not specifically developed for the field of health care, but they stand in harmony with the argument raised by others that it requires strategies beyond the identification of "bad apples" to strengthen ethical and professional behaviors in health care organizations. ${ }^{24,33}$ We require a renewed focus on the environmental context where physicians practice (eg, communication practices, workload, payment, reward, and penalty policies).

\section{THE WAY FORWARD}

The exposure of patients, students, and professionals to unprofessional/unethical behaviors is not a new problem and it persists unsolved and tolerated by many institutions around the world. Although a systematic and comprehensive approach on how to prevent, reduce, and mitigate unethical/unprofessional behaviors in medical schools and other health care organizations is beyond the scope of the present essay, it is worth mentioning a few remarkable examples of promising efforts of several health care institutions.

Four of the most notable institutional professionalism programs developed to date were implemented at Brigham and Women's Hospital, Mount Sinai Medical Center, the University of Pennsylvania Health System, and Vanderbilt University School of Medicine. 2,15,16,34 Although each program has its own specificities they share many common elements. First, these programs stem from leadership commitment to the improvement of professional behavior in their institutions and they involve partnering with like-minded institutional champions to support the program's activities. With the exception of the University of Pennsylvania Health System, all of the programs involve the creation and sanction of an institutional code of professional conduct. All programs established a structure for centralized reportingincluding anonymous reporting - and management of professionalism concerns, as well as a tiered approach led by well-trained institutional leaders to deal with reports of unprofessional behaviors in a dignified way.

Dorsey and colleagues from the University of Southern Illinois conducted anonymous surveys asking medical students to name the "most professional" and the "least professional" faculty in each department, after which the dean would meet with the least profes- 
sional to discuss behavior. ${ }^{35}$ This simple strategy was associated with an improved behavioral pattern; following the meeting with the dean, none of the most unprofessional faculty received this designation again.

Todhunter et al developed a form for student assessment of faculty professionalism. ${ }^{36}$ This tool could be used by institutions not only for the provision of feedback but also to convey a message about professional behavioral expectations. Medical schools and health care institutions would send an even stronger message about the priority of ethical/professional behavior if positive results of such an assessment were adopted as a requirement for promotion.

Finally, a report by the University of Washington School of Medicine described how efforts to improve the professionalism of their students led to a systemwide change toward an "ecology of professionalism" involving faculty, residents and other health care professionals. ${ }^{37}$ Among the innovations: a "Professionalism Student Advisory Group" to provide feedback; the provision of extensive educational interventions on professionalism aimed at faculty and residents; the use by several departments of a similar method for the assessment of professional behavior for both residents and faculty; and the implementation of a project called "Patients as Teachers," in which patients are invited to tell students about how it feels to be a patient and perceptions on how the students could improve their clinical and professional skills.

\section{CONCLUSION}

Reports of unethical and unprofessional behavior in medical schools and health care organizations are neither novel nor unexpected. Because such behaviors are associated with medical errors, increased costs, and preventable harm to patients, professional organizations must strongly commit to change. These organizations must resist the temptation to limit their efforts to the search for "bad apples" and consider carefully the reasons why the health care field has been historically tolerant of such unacceptable circumstances. It shall then become clear that the task ahead involves exposing the hidden curriculum of health care professions in order to change the underlying culture of our institutions. This would represent nothing short of a revolution in the way we teach and practice, a revolution for which patients and professionals have been yearning for too long.

To read or post commentaries in response to this article, see it online at http://www.annfammed.org/content/13/2/176.

Submitted May 24, 2014; submitted, revised, October 16, 2014; accepted January 5, 2015.
Key words: medical education; professional ethics; professional competence; empathy

Acknowledgments: We are very grateful to our former student whose graduation speech inspired this manuscript, for reminding us of how we felt when we were students and that this is definitively not how the learning of medicine was ever supposed to be. We also feel indebted to the anonymous peer reviewers whose thoughtful comments provided major contributions to this manuscript.

\section{REFERENCES}

1. Brody H, Doukas D. Professionalism: a framework to guide medical education. Med Educ. 2014;48(10):980-987.

2. Shapiro J, Whittemore A, Tsen LC. Instituting a culture of professionalism: the establishment of a center for professionalism and peer support. Jt Comm J Qual Patient Saf. 2014;40(4):168-177.

3. Satterwhite RC, Satterwhite WM III, Enarson C. An ethical paradox: the effect of unethical conduct on medical students' values. J Med Ethics. 2000;26(6):462-465.

4. Hicks LK, Lin Y, Robertson DW, Robinson DL, Woodrow SI. Understanding the clinical dilemmas that shape medical students' ethical development: questionnaire survey and focus group study. BMJ. 2001;322(7288):709-710.

5. Mavis B, Sousa A, Lipscomb W, Rappley MD. Learning about medical student mistreatment from responses to the medical school graduation questionnaire. Acad Med. 2014;89(5):705-711.

6. Nagata-Kobayashi S, Maeno T, Yoshizu M, Shimbo T. Universal problems during residency: abuse and harassment. Med Educ. 2009;43(7):628-636.

7. Grogan MJ, Knechtges P. The disruptive physician: a legal perspective. Acad Radiol. 2013;20(9):1069-1073.

8. Brainard $A H$, Brislen HC. Viewpoint: learning professionalism: a view from the trenches. Acad Med. 2007;82(11):1010-1014.

9. Fnais $\mathrm{N}$, Soobiah $\mathrm{C}$, Chen $\mathrm{MH}$, et al. Harassment and discrimination in medical training: a systematic review and meta-analysis. Acad Med. 2014;89(5):817-827.

10. Neumann M, Edelhäuser $F$, Tauschel $D$, et al. Empathy decline and its reasons: a systematic review of studies with medical students and residents. Acad Med. 2011;86(8):996-1009.

11. Feudtner C, Christakis DA, Christakis NA. Do clinical clerks suffer ethical erosion? Students' perceptions of their ethical environment and personal development. Acad Med. 1994;69(8):670-679.

12. Billings ME, Lazarus ME, Wenrich M, Curtis JR, Engelberg RA. The effect of the hidden curriculum on resident burnout and cynicism. J Grad Med Educ. 2011;3(4):503-510.

13. D'Eon M, Lear N, Turner M, Jones C; Canadian Association of Medical Education. Perils of the hidden curriculum revisited. Med Teach. 2007;29(4):295-296.

14. Makary M. How to stop hospitals from killing us. Wall St J. http:/l online.wsj.com/news/articles/SB1000087239639044462010457800 8263334441352. Published Sep 22, 2012. Accessed Oct 7, 2014.

15. Dupree E, Anderson R, McEvoy MD, Brodman M. Professionalism: a necessary ingredient in a culture of safety. Jt Comm J Qual Patient Saf. 2011;37(10):447-455.

16. Hickson GB, Pichert JW, Webb LE, Gabbe SG. A complementary approach to promoting professionalism: identifying, measuring, and addressing unprofessional behaviors. Acad Med. 2007;82(11):1040-1048.

17. Sklar DP. Mistreatment of students and residents: why can't we just be nice? Acad Med. 2014;89(5):693-695.

18. Leape LL, Shore MF, Dienstag JL, et al. Perspective: a culture of respect, part 1: the nature and causes of disrespectful behavior by physicians. Acad Med. 2012;87(7):845-852. 
19. Karle H. Global standards and accreditation in medical education: a view from the WFME. Acad Med. 2006;81(12)(Suppl):S43-S48.

20. Tokashiki CA, Sitnik D, Santos IS, et al. Analise de processos de avaliação e acreditação de escolas médicas no Brasil e no mundo. http://www2.fm.usp.br/cedem/docs/relatorio2_final.pdf. Accessed Sep 25, 2014.

21. World Federation for Medical Education. WFME Global Standards for Quality Improvement. Copenhagen, WFME Office, University of Copenhagen; 2003.

22. Liaison Committee on Medical Education. Functions and structure of a medical school: tandards for accreditation of medical education programs leading to the MD degree. 2013. http://www.lcme.org/ publications/functions2013june.pdf.

23. Hafferty FW. Beyond curriculum reform: confronting medicine's hidden curriculum. Acad Med. 1998;73(4):403-407.

24. Leape LL, Shore MF, Dienstag JL, et al. Perspective: a culture of respect, part 2: creating a culture of respect. Acad Med. 2012;87(7):853-858.

25. Rosenstein AH, O'Daniel M. Disruptive behavior and clinical outcomes: perceptions of nurses and physicians. Am J Nurs. 2005;105(1):54-64, quiz 64-65.

26. Saxton $R$, Hines $T$, Enriquez $M$. The negative impact of nursephysician disruptive behavior on patient safety: a review of the literature. J Patient Saf. 2009;5(3):180-183

27. The Joint Commission. Behaviors that undermine a culture of safety. Sentin Event Alert 2008; No 40. http://www.jointcommission. org/assets/1/18/SEA_40.pdf. Accessed Oct 1, 2014.

28. Rosenstein $\mathrm{AH}, \mathrm{O}^{\prime}$ Daniel M. A survey of the impact of disruptive behaviors and communication defects on patient safety. Jt Comm J Qual Patient Saf. 2008;34(8):464-471.
29. Rawson JV, Thompson N, Sostre G, Deitte L. The cost of disruptive and unprofessional behaviors in health care. Acad Radiol. 2013;20(9):1074-1076.

30. Coulehan J. Viewpoint: today's professionalism: engaging the mind but not the heart. Acad Med. 2005;80(10):892-898.

31. Hafferty F. Viewpoint: the elephant in medical professionalism's kitchen. Acad Med. 2006;81(10):906-914.

32. Zimbardo PG. The Lucifer Effect: Understanding How Good People Turn Evil. New York, NY: Random House; 2007.

33. Lesser CS, Lucey CR, Egener B, Braddock CH III, Linas SL, Levinson W. A behavioral and systems view of professionalism. JAMA. 2010;304(24):2732-2737

34. Speck RM, Foster JJ, Mulhern VA, Burke SV, Sullivan PG, Fleisher LA. Development of a professionalism committee approach to address unprofessional medical staff behavior at an academic medical center. Jt Comm J Qual Patient Saf. 2014;40(4):161-167.

35. Dorsey JK, Roberts NK, Wold B. Feedback matters: the impact of an intervention by the dean on unprofessional faculty at one medical school. Acad Med. 2014;89(7):1032-1037.

36. Todhunter S, Cruess SR, Cruess RL, Young M, Steinert Y. Developing and piloting a form for student assessment of faculty professionalism. Adv Health Sci Educ Theory Pract. 2011;16(2):223-238.

37. Goldstein EA, Maestas RR, Fryer-Edwards K, et al. Professionalism in medical education: an institutional challenge. Acad Med. 2006;81(10):871-876

\section{Get the Annals of Family Medicine by E-mail}

Make sure you see every new issue

while it's fresh; have the table of

contents sent to you by e-mail for

easy access to articles of interest.

Don't miss important research.

Request the e-mail table of contents at

http://www2.highroadsolution.com/

aafp_annals_preference_center/search.aspx

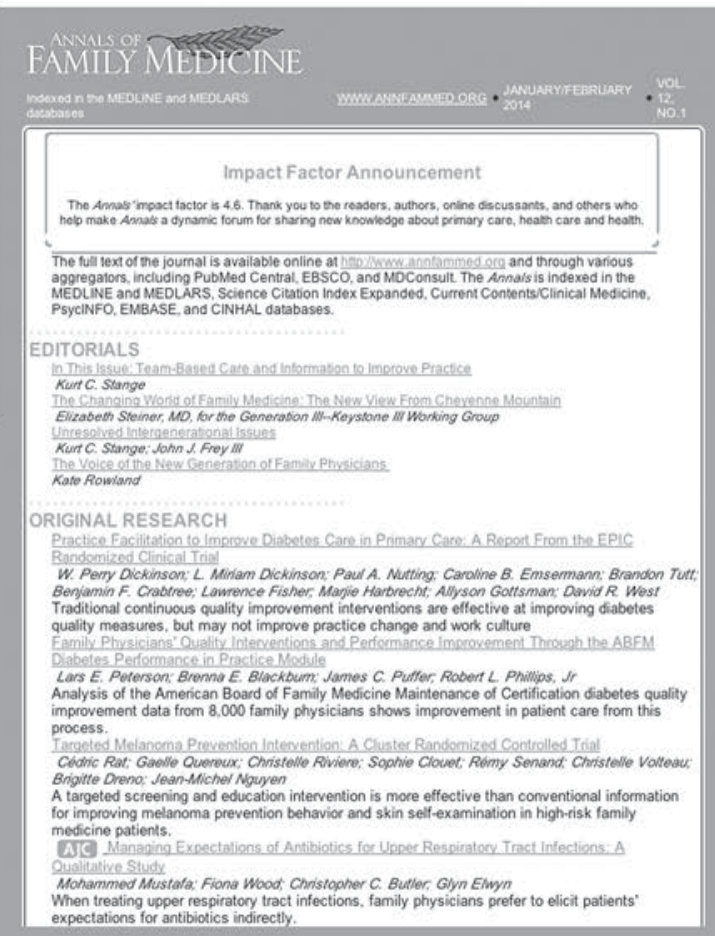

